\title{
No man is an island
}

\author{
The financial crisis underlines the need for new economic models - models that can only be built by \\ following a truly interdisciplinary approach.
}

When the Kiel Institute for the World Economy was founded in 1914, it was given the graceful name Königliches Institut für Seeverkehr und Weltwirtschaft - Royal Institute for Maritime Transport and the World Economy. The emphasis on maritime transport, however, was soon deemed outdated and dropped after twenty years, along with the reference to the King of Prussia.

The original name is a reminder of the role that maritime navigation played in building a truly global economy. Yet those relatively small trade networks have little in common with their modern counterparts: today, more goods and information are transported at an incomparably faster pace; many more players interact, in ever more sophisticated ways. But this increased connectivity has not only made the system more efficient and effective, it has also made it more difficult to understand to the point that it is unpredictable, as the current financial crisis plainly shows.

"Complexity starts when causality breaks down", said physicist Nigel Goldenfeld of the University of Illinois at a recent conference on complex systems (organized by the National Academies Keck Futures Initiative, a programme aiming to catalyse interdisciplinary research). Goldenfeld's statement is a beautifully succinct definition of the tipping point at which a simple system becomes 'complex'. For the financial markets, the tipping point has been passed - the US housing market hits trouble, and suddenly Iceland is on the brink of bankruptcy. Even more sobering is that, despite active research in the field (keeping many a physicist busy), the crisis, in this form and to this extent, was not predicted - or even thought possible.

What has gone wrong with economic theory? This question is discussed by Thomas Lux, a member of the scientific advisory board of the Kiel Institute of World Economics, and Frank Westerhoff in their Commentary on page 2 of this issue. They argue that the distinction made in natural sciences between phenomena on the micro-scale of single constituents and the macro-scale of the whole system has not reached mainstream economic theories. In economic models, the focus has been on a lone actor, a representative 'Robinson Crusoe', which carelessly neglects the reality of many heterogeneous agents interacting strongly and giving rise to emergent phenomena. Economics, say Lux and Westerhoff, has a lot to learn from the natural sciences.
Models of the financial markets as complex systems do already exist, under the banner of 'econophysics', but these certainly need much further refinement. There is also help to be had from other fields that deal with complex systems including sociology, epidemiology, ecology, engineering and brain research. Different as their specific objectives and systems of investigation are, the means of reaching a fuller understanding of the mechanisms at work are often quite similar between such fields (as even some of the mechanisms themselves may be). Data collection and handling, robustness of networks against failure and attacks, the need for early detection and prevention of failure and, not least, the fact that different networks interact with each other - these are topics relevant across all disciplines dealing with complex systems.

The solution to the financial crisis will not come through the application of physics alone, although physicists have much to contribute. Better models with more predictive power will arise only through close collaboration with economists who understand the details of the markets and through strong interaction within the wider complex-systems community.

\section{9 and all that}

\section{For the new year, we have a new look.}

This is the first issue of Volume 5 of Nature Physics, and with it comes a new look for our pages (or PDFs, if you're reading online). Every section of the journal - and of its sister titles, Nature Materials, Nature Nanotechnology,
Nature Photonics and Nature Geoscience - has been redesigned, refreshing the templates that we have used since our launch in 2005. The result, we hope you'll agree, is a look that is modern, effective and still distinctively ours.
The editorial team of Nature Physics also has a new look. We're pleased to welcome David Gevaux as the fifth member of the expanded team, taking the growing journal into its fourth year of publishing.
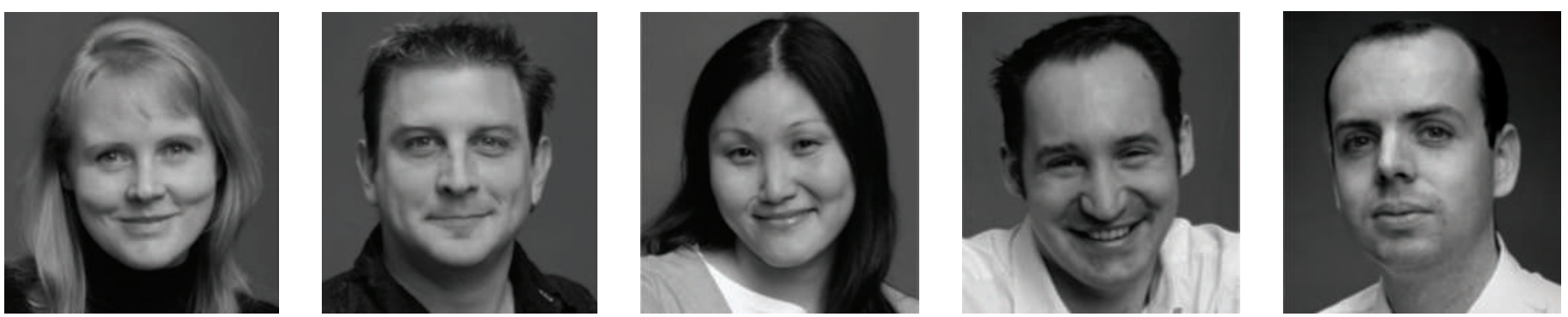

The editorial team: Alison Wright, Edmund Gerstner, May Chiao, Andreas Trabesinger and David Gevaux. 